\title{
Urgences
}

\section{Jean-Yves Dupuis, Vivement la vie, Montréal, Éditions Pierre Tisseyre, 1984.}

\section{Martine Lemieux}

Numéro 12, 3e trimestre 1984

\section{Spécial humour}

URI : https://id.erudit.org/iderudit/025189ar

DOI : https://doi.org/10.7202/025189ar

Aller au sommaire du numéro

\section{Éditeur(s)}

Urgences

\section{ISSN}

0226-9554 (imprimé)

1927-3924 (numérique)

Découvrir la revue

Citer ce compte rendu

Lemieux, M. (1984). Compte rendu de [Jean-Yves Dupuis, Vivement la vie, Montréal, Éditions Pierre Tisseyre, 1984.] Urgences, (12), 76-78.

https://doi.org/10.7202/025189ar

Ce document est protégé par la loi sur le droit d'auteur. L’utilisation des services d'Érudit (y compris la reproduction) est assujettie à sa politique d'utilisation que vous pouvez consulter en ligne.

https://apropos.erudit.org/fr/usagers/politique-dutilisation/
Cet article est diffusé et préservé par Érudit.

Érudit est un consortium interuniversitaire sans but lucratif composé de l'Université de Montréal, l'Université Laval et l'Université du Québec à Montréal. Il a pour mission la promotion et la valorisation de la recherche. https://www.erudit.org/fr/ 


\section{PARUTIONS COMMENTÉES}

VIVEMENT LA VIE, de Jean-Yves Dupuis, Ed., Pierre Tisseyre, 1984.

Une histoire qui s'annonce amusante. Quatre jeunes gens dans la vingtaine, trois soeurs et un frère, héritent d'une maison à la campagne, agréable invitation à la liberté, au changement. Le frère nous donne à lire son journal dans lequel il raconte les situations cocasses et parfois dramatiques que vivent ses soeurs et lui. Son amie Marie et les gens du village passeront de mauvais quarts d'heure en compagnie de cette famille peu ordinaire. En effet, leur complicité naturelle et

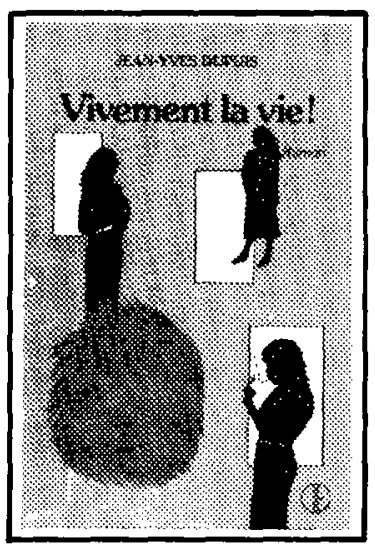

sympathique repose sur des habitudes peu acceptées socialement: ils sont sans pudeur ni complexes et ce, autant physiquement que verbalement, et arrosent le tout de leur denrée préférée, l'alcool. Le lecteur suit les personnages à travers de nombreuses péripéties. Comme toile de fond se dessine la relation tendre et incestueuse entre Julie, la plus jeune des soeurs, et son frère. Julie est une fille peu bavarde, alcoolique et apathique. L'histoire se termine mal, car comme le dira Catherine (une autre soeur): "on (a) beau être larges d'esprit, il y a tout de même des choses qui ne se font pas dans le monde" 
(p. 184). Julie quittera son frère et celui-ci clôt son journal bien tristement: "C'était vraiment idiot de s'amouracher de sa soeur!..." (p. 228). Voilà une histoire empreinte de tendresse, mais surtout d'humour, qui met en scène des personnages libérés des responsabilités et des conventions sociales.

J'ai été séduite par le style familier et vivant de l'auteur. Le ton du récit, léger et humoristique, concourt à créer l'unité du roman. Une écriture rythmée qui suscite beaucoup d'intérêt. Toutefois, l'accumulation des "j'ai dit", "elle a dit", "elle a ajouté", utilisés pour rapporter les conversations, alourdit parfois le texte.

Certains éléments, dans la forme même du journal, ont aussi gêné ma lecture. Ainsi, ce narrateur, nommé pour la première fois vers la fin du roman, s'appelle Jean-Yves Dupuis, comme l'auteur. En outre, le journal devient un objet du récit lorsque Julie, l'ayant lu, s'interroge sur sa véracité, y ajoute son mot ou en détruit quelques pages. Quel est le sens de ces jeux de miroir entre le journal d'un des personnages et le roman de l'auteur? Les indices, trop peu nombreux pour être efficaces dérangent plus qu'ils ne surprennent ou amusent.

Autre déplaisir, à quelques reprises le narrateur convoque directement le lecteur, soit po' 'le prévenir, en annonçant un passage osé, soit pour prendre la défense de Julie: "Et toi, bon lecteur, avant de la condamner, réfléchis bien. Que celui qui ne s'est jamais soûlé jette ce livre par la fenêtre" (p. 122). Or, même sans blesser votre pudeur ou susciter de votre pan des jugements (condamner un personnage ne me viendrait pas à l'idée), il n'en demeure pas moins, qu'à la longue, ces descriptions de soûleries peuvent agacer ou lasser.

Mais revenons à ce narrateur qui par l'intermédiaire du journal nous prête ses yeux. Car c'est bien d'un regard qu'il s'agit et celui-ci se pose habituellement sur le corps des femmes. Ces images sont parfois amusantes, mais souvent indiscrètes surtout lorsqu'elles montrent les fonctions physiologiques du corps. Enfin, le lecteur intéressé pourra en "visua- 
liser" beaucoup...

Cette obsession, commune à tous les personnages, occulte les autres situations dramatiques. Le départ de Marie, le détachement des soeurs et la vente de la maison n'ont pas de poids. Reste la relation avec Julie où le personnage-narrateur s'investit le plus émotivement. II y a là la matière d'un roman érotique. Mais il ne suffit pas de voir et de nommer les parties d'une anatomie pour produire un effet d'érotisme. La sensation est souvent absente de ces descriptions que j'ai trouvées techniques et par conséquent froides.

L'inceste, ce comportement caché et peu expliqué, serat-il mieux compris ou permettra-t-il d'ouvrir de nouvelles voies? Pas vraiment, si ce n'est le changement radical de Julie devenue "une fille comme toutes les autres filles" (p. 226), avec un appartement à elle, un travail, un ami et des activités intéressantes.

Martine Lemieux

LA PARADE, de Noël Audet, Ed. Québec Amérique, 1984.

II y a des enthousiasmes qui ne pardonnent pas... Comme c'est coupe-gorge, parfois, un bon premier roman!

Ayant beaucoup aimé Quand la voile faseille, premier roman de Noël Audet, c'est avec plaisir que j'ai accepté de lire ce troisième roman, La Parade. Hélas! en migrant à la ville, l'écriture a aussi perdu sa belle vitalité... Si, dans l'univers gaspésien, les mots jouaient à saute-mouton, se bousculaient, s'amusaient à des bonheurs d'expression tout à fait savoureux; si la parole y culbutait et y pirouettait comme une acrobate, ici... les jeux de mots, presque forcés, prennent des allures anémiques (à vous de juger: "mon père putatif (Le Tif à putes)" (page 13) ou encore "son mascara - Ton masque-à-rat coule!" (page 87). Les personnages eux-mêmes, touchés par la contagion, se comprennent à coups de "hé! hé!" et de 